\title{
Pharmacologic management of autism spectrum disorder: A review of 7 studies
}

Radhika J. Kothadia, MD, Matthew Krause, DO, and Sy Atezaz Saeed, MD, MS

A utism spectrum disorder (ASD) is characterized by persistent deficits in social communication and social interaction, including deficits in social reciprocity, nonverbal communicative behaviors used for social interaction, and skills in developing, maintaining, and understanding relationships. ${ }^{1}$ In addition, the diagnosis of ASD requires the presence of restricted, repetitive patterns of behavior, interests, or activities.

Initially, ASD was considered a rare condition. In recent years, the reported prevalence has increased substantially. The most recent estimated prevalence is 1 in 68 children at age 8 , with a male-to-female ratio of 4 to $1 .^{2}$

Behavioral interventions are considered to be the most effective treatment for the core symptoms of ASD. Pharmacologic interventions are used primarily to treat associated or comorbid symptoms rather than the core symptoms. Aggression, self-injurious behavior, and irritability are common targets of pharmacotherapy in patients with ASD. Studies have provided support for the use of antipsychotic agents to treat irritability and associated aggressive behaviors in patients with autism, ${ }^{3}$ but because these agents have significant adverse effects-including extrapyramidal side effects, somnolence, and weight gain-their use requires a careful risk/benefit assessment. Stimulants have also been shown to be effective in treating comorbid attention-deficit/hyperactivity symptoms. The use of selective serotonin reuptake inhibitors (SSRIs) to manage repetitive behaviors and anxiety is also common.
Here, we review 7 recent studies of the pharmacologic management of ASD (Table, ${ }^{4-10}$ page 34). These studies examined the role of SSRIs (sertraline, fluoxetine), an acetylcholinesterase inhibitor (donepezil), atypical antipsychotics (risperidone, aripiprazole, lurasidone), natural supplements (vitamin D, omega-3), a diuretic (bumetanide), and a glutamatergic modulator (riluzole) in the treatment of ASD symptoms.

\section{Potter LA, Scholze DA, Biag HMB, et al. A randomized controlled trial of sertraline in young children with autism spectrum disor- der. Front Psychiatry. 2019;10:810.}

Several studies have shown that SSRIs improve language development in children with Fragile X syndrome, based on the Mullen Scales of Early Learning (MSEL). A previously published trial involving children with Fragile $X$ syndrome and comorbid ASD found that sertraline improved expressive language development. Potter et $\mathrm{al}^{4}$ examined the role of sertraline in children with ASD only.

continued

Dr. Kothadia is a PGY-1 Psychiatry Resident, Prisma Health-Midlands, Columbia, South Carolina. Dr. Krause is a Child \& Adolescent Psychiatrist, Primary Health Network, Latrobe, Pennsylvania. Dr. Saeed is Professor and Chair, Department of Psychiatry and Behavioral Medicine, East Carolina University Brody School of Medicine, Greenville, North Carolina. Dr. Saeed is CURRENT PsYCHIATRY's Department Editor, Psychiatry Journal Club.

Disclosures

The authors report no financial relationships with any companies whose products are mentioned in this article, or with manufacturers of competing products.

doi: $10.12788 /$ cp.0078

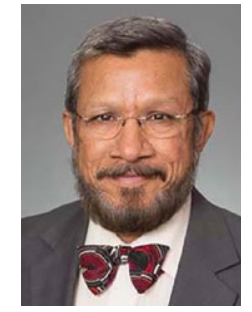

Sy Atezaz Saeed, MD Department Editor

Evidence suggests some agents might help treat irritability and other symptoms associated with ASD 


\section{Clinical Point}

\section{SSRIs do not}

appear to improve expressive language in children with ASD who do not have Fragile $X$ syndrome

\section{Table}

\section{Pharmacologic management of autism spectrum disorder: 7 studies}

\begin{tabular}{|c|c|c|}
\hline Study & Design & Outcomes \\
\hline $\begin{array}{l}\text { Potter } \\
\text { et } \mathrm{al}^{4}\end{array}$ & $\begin{array}{l}58 \text { children with ASD age } 24 \text { to } 72 \text { months } \\
\text { were randomly assigned to receive low- } \\
\text { dose sertraline or placebo for } 6 \text { months } \\
\text { to evaluate for improvement in expressive } \\
\text { language development }\end{array}$ & $\begin{array}{l}\text { No significant differences were found on } \\
\text { the primary outcome (MSEL expressive } \\
\text { language raw score and age-equivalent } \\
\text { combined score) or secondary outcomes }\end{array}$ \\
\hline $\begin{array}{l}\text { Gabis } \\
\text { et } a^{5}\end{array}$ & $\begin{array}{l}60 \text { children and adolescents with ASD were } \\
\text { randomly assigned to receive placebo or } \\
\text { donepezil plus a choline supplement }\end{array}$ & $\begin{array}{l}\text { Patients age } 5 \text { to } 10 \text { years treated with } \\
\text { donepezil plus a choline supplement } \\
\text { exhibited improved receptive language } \\
\text { skills. However, this treatment was less } \\
\text { effective in patients age }>10 \text {, and this } \\
\text { group also exhibited worsening behavior }\end{array}$ \\
\hline $\begin{array}{l}\text { James } \\
\text { et } \mathrm{al}^{6}\end{array}$ & $\begin{array}{l}\text { Review of } 3 \text { RCTs that evaluated the effects } \\
\text { of low-dose oral bumetanide in } 208 \text { children } \\
\text { and adolescents with ASD }\end{array}$ & $\begin{array}{l}\text { Bumetanide improved social } \\
\text { communication, social interactions, } \\
\text { and restricted interests in patients with } \\
\text { moderate to severe ASD. However, the } 3 \\
\text { studies used different evaluation methods } \\
\text { and noted varying degrees of improvement }\end{array}$ \\
\hline Li et $\mathrm{al}^{7}$ & $\begin{array}{l}\text { Meta-analysis of } 13 \text { studies of } 303 \text { patients } \\
\text { with ASD (average age: } 15 \text { years) who } \\
\text { received fluoxetine }\end{array}$ & $\begin{array}{l}75 \% \text { of participants responded to } \\
\text { fluoxetine. However, limitations of this } \\
\text { meta-analysis included low power, } \\
\text { inadequate quality of the included studies, } \\
\text { and high statistical heterogeneity }\end{array}$ \\
\hline $\begin{array}{l}\text { Fallah } \\
\text { et al }\end{array}$ & $\begin{array}{l}\text { Review and meta-analysis of } 8 \text { studies } \\
\text { that compared the efficacy of risperidone, } \\
\text { aripiprazole, lurasidone, and placebo for } \\
\text { treating irritability in } 878 \text { patients with ASD }\end{array}$ & $\begin{array}{l}\text { Risperidone reduced } \mathrm{ABC}-\mathrm{I} \text { scores more } \\
\text { than aripiprazole, lurasidone, or placebo }\end{array}$ \\
\hline $\begin{array}{l}\text { Mazahery } \\
\text { et al }{ }^{9}\end{array}$ & $\begin{array}{l}73 \text { children age } 2.5 \text { to } 8 \text { years with ASD } \\
\text { were randomly assigned to receive vitamin } \\
D, 2000 \mathrm{IU} / \mathrm{d} \text {, omega-3 LCPUFA, } 722 \mathrm{mg} / \mathrm{d} \text {, } \\
\text { or both }\end{array}$ & $\begin{array}{l}\text { Treatment with vitamin D reduced irritability } \\
\text { and hyperactivity. Treatment with omega-3 } \\
\text { LCPUFA reduced hyperactivity and } \\
\text { lethargy }\end{array}$ \\
\hline $\begin{array}{l}\text { Wink } \\
\text { et } \mathrm{al}^{10}\end{array}$ & $\begin{array}{l}8 \text { patients age } 12 \text { to } 25 \text { with ASD and drug- } \\
\text { refractory irritability were randomly assigned } \\
\text { to receive adjunctive riluzole }\end{array}$ & $\begin{array}{l}\text { No significant treatment effects were } \\
\text { identified }\end{array}$ \\
\hline
\end{tabular}

\section{Study design}

- In this randomized, double-blind, placebo-controlled trial, 58 children age 24 to 72 months with ASD received lowdose sertraline or placebo for 6 months.

- Of the 179 participants who were screened for eligibility, 58 were included in the study. Of these 58 participants, 32 received sertraline and 26 received placebo. The numbers of participants who discontinued from the sertraline and placebo arms were 8 and 5 , respectively.

- Among those in the sertraline group, participants age $<48$ months received
$2.5 \mathrm{mg} / \mathrm{d}$, and those age $\geq 48$ months received $5 \mathrm{mg} / \mathrm{d}$.

\section{Outcomes}

- No significant differences were found on the primary outcome (MSEL expressive language raw score and age-equivalent combined score) or secondary outcomes (including Clinical Global ImpressionsImprovement [CGI-I] scale at 3 months and end of treatment), as per intent-to-treat analyses.

- Sertraline was well tolerated. There was no difference in adverse effects 
between treatment groups and no serious adverse events.

\section{Conclusion}

- Although potentially useful for language development in patients with Fragile $X$ syndrome with comorbid ASD, SSRIs such as sertraline have not proven efficacious for improving expressive language in patients with non-syndromic ASD.

-While 6-month treatment with lowdose sertraline in young children with ASD appears safe, the long-term effects are unknown.

\section{Gabis LV, Ben-Hur R, Shefer S, et al.} Improvement of language in children with autism with combined donepezil and choline treatment. J Mol Neurosci. 2019; 69(2):224-234.

Gabis et $a l^{5}$ examined the safety and efficacy of utilizing donepezil, an acetylcholinesterase inhibitor, plus a choline supplement to treat both core features and associated symptoms in children and adolescents with ASD.

\section{Study design}

- This 9-month randomized, doubleblind trial included 60 children/adolescents with ASD who were randomly assigned to receive placebo or donepezil plus a choline supplement. Participants underwent a baseline evaluation (E1), 12 weeks of treatment and re-evaluation (E2), 6 months of washout, and a final evaluation (E3).

- The baseline and final evaluations assessed changes in language performance, adaptive functioning, sleep habits, autism severity, clinical impression, and intellectual abilities. The evaluation after 12 weeks of treatment (E2) included all of these measures except intellectual abilities.

\section{Outcomes}

- Patients treated with donepezil plus a choline supplement had significant improvement in receptive language skills between E1 and E3 $(P=.003)$.

- Patients treated with donepezil plus a choline supplement had significant worsening in scores on the Autism Treatment Evaluation Checklist (ATEC) health/physical behavior subscale between E1 and E2 $(P=.012)$ and between E1 and E3 $(P=.021)$.

- Improvement in receptive language skills was significant only in patients age 5 to 10 years $(P=.047)$, whereas worsening in ATEC health/physical behavior subscale score was significant only in patients age 10 to 16 years $(P=.024)$.

- Patients treated with donepezil plus a choline supplement reported higher percentages of gastrointestinal disturbance when compared with placebo $(P=.007)$, and patients in the adolescent subgroup had a significant increase in irritability $(P=.035)$.

\section{Conclusion}

- Patients age 5 to 10 years treated with donepezil plus a choline supplement exhibited improved receptive language skills. This treatment was less effective in patients age $>10$ years, and this group also exhibited behavioral worsening.

- Gastrointestinal disturbances were the main adverse effect of treatment with donepezil plus a choline supplement.

\section{James BJ, Gales MA, Gales BJ. Bumetanide for autism spectrum disorder in children: a review of randomized controlled trials. Ann Pharmacother. 2019;53(5):537-544.}

The persistence of excitatory gamma-aminobutyric acid (GABA) signaling has been found in patients with ASD. Bumetanide is a sodium-potassium-chloride cotransporter 1 (NKCC1) antagonist that not only decreases intracellular chloride, but also aberrantly decreases GABA signaling. This potent loop diuretic is a proposed treatment for symptoms of ASD. James et $\mathrm{al}^{6}$ evaluated the safety and efficacy of bumetanide use in children with ASD.

\section{Clinical Point}

In patients age 5
to 10 with ASD,
donepezil plus a
choline supplement
improved receptive
language skills




\section{Clinical Point}

\section{Bumetanide improved social communication and social interactions in patients with moderate to severe ASD}

\section{Study design}

- Researchers searched the PubMed and Ovid MEDLINE databases for the terms "autism" and "bumetanide" between 1946 and 2018. A total of 26 articles were screened by title, 7 were screened by full text, and 3 articles were included in the study. The remaining articles were excluded due to study design and use of non-human subjects.

- All 3 randomized controlled trials evaluated the effects of low-dose oral bumetanide (most common dose was $0.5 \mathrm{mg}$ twice daily) in a total of 208 patients age 2 to 18 years.

- Measurement scales used in the 3 studies included the Childhood Autism Rating Scale (CARS), Clinical Global Impressions Scale (CGI), Autism Behavioral Checklist (ABC), Social Responsiveness Scale (SRS), and Autism Diagnostic Observation ScheduleGeneric (ADOS-G).

\section{Outcomes}

- Bumetanide improved scores on multiple autism assessment scales, including CARS, but the degree of improvement was not consistent across the 3 trials.

- There was a statistically significant improvement in ASD symptoms as measured by CGI in all 3 trials, and statistically significant improvements on the $\mathrm{ABC}$ and SRS in 2 trials. No improvements were noted on the ADOS-G in any of the trials.

- No dose-effect correlation was identified, but hypokalemia and polyuria were more prevalent with higher doses of bumetanide.

\section{Conclusion}

- Low-dose oral bumetanide improved social communication, social interactions, and restricted interests in patients with moderate to severe ASD. However, the 3 trials used different evaluation methods and observed varying degrees of improvement, which makes it difficult to make recommendations for or against the use of bumetanide.

- Streamlined trials with a consensus on evaluation methodology are needed to draw conclusions about the efficacy and safety of bumetanide as a treatment for ASD.
4. Li C, Bai Y, Jin C, et al. Efficacy and safety of fluoxetine in autism spectrum disorder: a metaanalysis. Am JTher. 2020;27(3):e312-e315.

The use of SSRIs to target symptoms of ASD has been long studied because many children with ASD have elevated serotonin levels. Several SSRIs, including fluoxetine, are FDAapproved for the treatment of obsessive-compulsive disorder, anxiety, and depression. Currently, no SSRIs are FDA-approved for treating ASD. In a meta-analysis, $\mathrm{Li}$ et $\mathrm{al}^{7}$ evaluated the use of fluoxetine for ASD.

\section{Study design}

- Two independent researchers searched for studies of fluoxetine treatment for ASD in Embase, Google Scholar, Ovid SP, and PubMed, with disagreement resolved by consensus.

- The researchers extracted the study design, patient demographics, and outcomes (inter-rater reliability kappa $=0.93$ ). The primary outcomes were response rate of patients treated with fluoxetine, and change from baseline in ABC, ATEC, CARS, CGI, and Yale-Brown Obsessive Compulsive Scale (Y-BOCS) scores after fluoxetine treatment.

\section{Outcomes}

- This meta-analysis included 13 studies in which fluoxetine was used to treat a total of 303 patients with ASD. The median treatment duration was 6 months, the average age of participants was 15.23 years, and most participants $(72 \%)$ were male.

- The response rate of patients treated with fluoxetine was $75 \%$, with significant mean changes from baseline in ABC score (-3.42), ATEC score $(-2.04)$, CGI score $(-0.93)$, and Y-BOCS score $(-1.86)$.

- A significantly higher incidence of hyperactivity/restlessness/agitation was noted with fluoxetine.

\section{Conclusion}

- Although $75 \%$ of participants responded to fluoxetine, the limitations of this meta- 
analysis included low power, inadequate quality of the included studies, and high statistical heterogeneity. In addition, the analysis found a high incidence of hyperactivity/restlessness associated with fluoxetine.

- Future randomized controlled studies may provide further clarification on managing symptoms of ASD with SSRIs.

5. Fallah MS, Shaikh MR, Neupane B, et al. Atypical antipsychotics for irritability in pediatric autism: a systematic review and network meta-analysis. J Child Adolesc Psychopharmacol. 2019;29(3):168-180.

Irritability is a common comorbid symptom in children with ASD. Two second-generation antipsychotics (SGAs)—risperidone and aripiprazole-are FDA-approved for irritability associated with ASD. Fallah et $\mathrm{al}^{8}$ examined the efficacy of several SGAs for treating irritability.

\section{Study design}

- This review and meta-analysis included 8 studies identified from Medline, PsycINFO, and Embase from inception to March 2018. It included double-blind, randomized controlled trials that used the Aberrant Behavior Checklist Irritability (ABC-I) to measure irritability.

- The main outcome was change in degree of irritability.

- The 8 studies compared the efficacy of risperidone, aripiprazole, lurasidone, and placebo in a total of 878 patients.

\section{Outcomes}

- Risperidone reduced ABC-I scores more than aripiprazole, lurasidone, or placebo.

- Mean differences in ABC-I scores were -6.89 for risperidone, -6.62 for aripiprazole, and -1.61 for lurasidone.

\section{Conclusion}

- Risperidone and aripiprazole were efficacious and safe for children with ASDassociated irritability.
- Lurasidone may minimally improve irritability in children with ASD.

6. Mazahery H, Conlon CA, Beck KL, et al. A randomised controlled trial of vitamin $D$ and omega-3 long chain polyunsaturated fatty acids in the treatment of irritability and hyperactivity among children with autism spectrum disorder. J Steroid Biochem Mol Biol. 2019;187:9-16.

Irritability and hyperactivity are common comorbid symptoms in children with ASD and have been linked to lower quality of life, poor adaptive functioning, and lower responsiveness to treatments when compared to children without comorbid problem behaviors. Mazahery et $\mathrm{al}^{9}$ evaluated the efficacy of vitamin $\mathrm{D}$, omega-3 long-chain polyunsaturated fatty acids (LCPUFA), or both on irritability and hyperactivity.

\section{Study design}

- In a 1-year, double-blind, placebocontrolled trial, 73 children age 2.5 to 8 years with ASD were randomly assigned to receive placebo; vitamin $\mathrm{D}, 2000 \mathrm{IU} / \mathrm{d}$ (VID); omega-3 LCPUFA, 722 mg/d (OM); or both in the aforementioned doses.

- The primary outcome was reduction in the Aberrant Behavior Checklist in the domains of irritability and hyperactivity. Caregivers also completed weekly surveys regarding adverse events, compliance, and utilization of behavioral therapies.

- Of 111 children enrolled, 73 completed the 12 months of treatment.

\section{Outcomes}

- Children who received OM and VID had a greater reduction in irritability than those who received placebo $(P=.001$ and $P=.01$, respectively).

- Children who received VID also had a reduction in irritability $(P=.047)$.

- An explanatory analysis revealed that $\mathrm{OM}$ also reduced lethargy (based on the Aberrant Behavior Checklist) more
Clinical Point

Risperidone
reduced irritability
scores more than
aripiprazole,
lurasidone, or
placebo




\section{Clinical Point}

Treatment with vitamin $D$ reduced irritability and hyperactivity in 73 children with ASD significantly than placebo $(P=.02$ adjusted for covariates).

\section{Conclusion}

- Treatment with vitamin D, $2000 \mathrm{IU} / \mathrm{d}$, reduced irritability and hyperactivity.

- Treatment with omega-3 LCPUFA, $722 \mathrm{mg} / \mathrm{d}$, reduced hyperactivity and lethargy.

\section{Wink LK, Adams R, Horn PS, et al. A ran-} domized placebo-controlled cross-over pilot study of riluzole for drug-refractory irritability in autism spectrum disorder. J Autism Dev Disord. 2018;48(9):3051-3060.

Glutamatergic dysregulation has been identified as a potential cause of ASD. Riluzole, a glutamatergic modulator that is FDAapproved for treating amyotrophic lateral sclerosis, is a drug of interest for the treatment of ASD-related irritability due to this proposed mechanism. Wink et al ${ }^{10}$ evaluated riluzole for irritability in patients with ASD.

\section{Study design}

- This randomized, double-blind, placebocontrolled, crossover pilot study evaluated the tolerability and safety of adjunctive riluzole treatment for drug-refractory irritability in 8 patients with ASD.

- Participants were age 12 to 25 years, had a diagnosis of ASD confirmed by the autism diagnostic observation schedule 2 , and an ABC-I subscale score $\geq 18$. Participants receiving $\geq 2$ psychotropic medications or glutamatergic/GABA-modulating medications were excluded.

- Participants received either 5 weeks of riluzole followed by 5 weeks of placebo, or vice versa; both groups then had a 2-week washout period.

- Riluzole was started at $50 \mathrm{mg} / \mathrm{d}$, and then increased in $50 \mathrm{mg} / \mathrm{d}$-increments to a maximum of $200 \mathrm{mg} / \mathrm{d}$ by Week 4 .
- Primary outcome measures were change in score on the ABC-I and CGI-I.

\section{Outcomes}

- No significant treatment effects were identified.

- All participants tolerated riluzole, $200 \mathrm{mg} / \mathrm{d}$, but increased dosages did not result in a higher overall treatment effect.

- There were no clinically significant adverse effects or laboratory abnormalities.

\section{Conclusion}

- Riluzole, $200 \mathrm{mg} / \mathrm{d}$, was well tolerated but had no significant effect on irritability in adolescents with ASD.

\section{References}

1. Diagnostic and statistical manual of mental disorders, 5th ed. American Psychiatric Association; 2013.

2. Christensen DL, Baio J, Van Naarden Braun K, et al Centers for Disease Control and Prevention. Prevalence and characteristics of autism spectrum disorder among children aged 8 years: Autism and Developmental Disabilities Monitoring Network, 11 sites, United States, 2012. MMWR Surveill Summ. 2016;65(3):1-23.

3. Fung LK, Mahajan R, Nozzolillo A, et al. Pharmacologic treatment of severe irritability and problem behaviors in autism: a systematic review and meta-analysis. Pediatrics. 2016;137(suppl 2):S124-S135.

4. Potter LA, Scholze DA, Biag HMB, et al. A randomized controlled trial of sertraline in young children with autism spectrum disorder. Front Psychiatry. 2019;10:810.

5. Gabis LV, Ben-Hur R, Shefer S, et al. Improvement of languageinchildren withautism with combined donepezil and choline treatment. J Mol Neurosci. 2019;69(2): 224-234.

6. James BJ, Gales MA, Gales BJ. Bumetanide for autism spectrum disorder in children: a review of randomized controlled trials. Ann Pharmacother. 2019;53(5) 537-544.

7. Li C, Bai Y, Jin C, et al. Efficacy and safety of fluoxetine in autism spectrum disorder: a meta-analysis. Am J Ther. 2020;27(3):e312-e315

8. Fallah MS, Shaikh MR, Neupane B, et al. Atypical antipsychotics for irritability in pediatric autism: a systematic review and network meta-analysis. J Child Adolesc Psychopharmacol. 2019;29(3):168-180.

9. Mazahery $\mathrm{H}$, Conlon $\mathrm{CA}$, Beck $\mathrm{KL}$, et al. A randomised controlled trial of vitamin D and omega-3 long chain polyunsaturated fatty acids in the treatment of irritability and hyperactivity among children with autism spectrum disorder. J Steroid Biochem Mol Biol. 2019;187:9-16.

10. Wink LK, Adams R, Horn PS, et al. A randomized placebo-controlled cross-over pilot study of riluzole for drug-refractory irritability in autism spectrum disorder. J Autism Dev Disord. 2018;48(9):3051-3060. 